\title{
The effect of biochar filler on the hydration products and microstructure in Portland cement stabilized peat
} peat results in an increase of unconfined compressive strength, comparable with that of a sand filler. Strength increase is significantly higher when biochar is ground to a size below $75 \mu \mathrm{m}$. This paper investigates the changes in mineralogy, texture and microstructure during the early hydration of cement mixed with peat and biochar filler Trumpington Street, Cambridge CB2 1PZ, UK, Email:jeffreylauze@gmail.com

\section{ABSTRACT}

Laboratory tests demonstrated that biochar filler added to Portland cement stabilized to identify the mechanisms responsible for the strength increase. The results show that the biochar surface catalyzes nucleation of hydration products. Labile carbon in biochar promotes carbonation, with precipitation of calcite within its cells and on its surface, as well as formation of hemi and monocarboaluminate, two stable AFm phases. For the 
20 larger fragments of biochar, the early hydration products do not reach the inner cells.

21 Instead, the fine fragments tend to be fully covered leading to a more homogeneous

22 spatial distribution of cement and voids.

\section{INTRODUCTION}

24 Peat soil is a type of soft soil with extremely high organic and water contents. It forms

25 from the accumulation of undecomposed and partially decomposed organic matter, in a

26 water saturated environment (up to $1000 \%$ water content) where scarcity of oxygen and

27 reducing conditions favor preservation of organics. Peat soils are widespread in

28 temperate and cold zones of the northern hemisphere and in the lowland areas of

29 Southeast Asia (Osman 2018). One of the major issues with construction on peat soil is its

30 high compressibility, causing structures to experience large undesirable differential

31 settlement. Chemical stabilization by using artificial binders has been largely successful

32 in treating soft soil. When chemical binders, such as cement, are added to soil in the

33 presence of water, cementitious and pozzolanic reactions occur to form cementitious gels

34 which increase the strength of the soil matrix. Organic matter in peat inhibits or slows

35 down these reactions (Tremblay, et al. 2002). Therefore, a large quantity of binder is

36 required before a significant strength gain is observed (Janz and Johansson 2002).

37 Typically, sand is added to the stabilization mix as an inert filler, to reduce the amount

38 of binder required. Urbanization driven, rapid growth of global cement production has

39 escalated the extent of sand mining to surpass natural renewal rates (Larson 2018) thus 
making the search for alternative fillers a critical need.

Lau et al. (2019) propose biochar as a sustainable, highly available alternative to sand. As biochar can be produced from local biomass, usually abundant in regions with peat soil, it can supply filler for treatments of large volumes of soil, such as in transportation infrastructure application (e.g. road sub-base). Biochar is the carbon-rich product of the pyrolysis of biomass. It stores Carbon in a recalcitrant form, significantly slowing down its re-emission into the atmosphere as $\mathrm{CO}_{2}$ (Woolf, et al. 2010). According to Lehman and Joseph (2015), a sustainable conversion of $1 \%$ annual plant uptake into biochar can reduce atmospheric $\mathrm{CO}_{2}$ by $10 \%$ of current anthropogenic emissions.

Biochar most common application is in soil amendment because its water and nutrient retention capacity lead to a significant improvement in crop productivity (Woolf, et al. 2010, Bruun, et al. 2014, Lehmann and Joseph 2015). Additionally, biochar has been investigated for removal of pollutants (Park, et al. 2011, Tan, et al. 2015), as a catalyst, in fuel cells and other environmental applications (Qian, et al. 2015). In recent years, the feasibility of using biochar in construction material has been explored (Gupta and Kua 2017, Gupta, et al. 2018, Dixit, et al. 2019, Wang, et al. 2020). A few studies showed that addition of $1-2 \%$ hardwood-derived biochar to Ordinary Portland Cement (OPC) accelerates hydration, with a corresponding increase of unconfined compressive strength (UCS), at seven days (Gupta, et al. 2018, Dixit, et al. 2019, Wang, et al. 2020). Gupta et al. (2018) proposed that slowly released water by the biochar promotes formation of 
60 hydration products. Dixit et al. (2019) noted a positive effect of fine-size biochar $(<150$

$61 \mu \mathrm{m})$ filler on the early hydration rate in ultra-high performance concrete. The correlation

62 between fine size and faster hydration has been shown for sand fillers too and has been

63 attributed to a better filling of the space by fine particles. Wang et al. (2020) tested the

64 effect of $\mathrm{CO}_{2}$ curing of OPC with biochar filler (1\%). They observed carbonation of

65 portlandite and faster rate of hydration, with an overall positive effect on strength.

66 Lau et al. (2019) tested the effect on compressive strength of a biochar filler added to

67 high-water-content peat OPC mixtures, compared to a sand filler. Results showed

68 comparable performance between the two. Most importantly, UCS of mixtures made

69 with biochar ground to a fine particle size ( $<75 \mathrm{um})$ decisively surpassed that of mixtures

70 made with equivalent size and weight of sand. This unexpected, measurable difference

71 in UCS, clearly related to the presence of fine-grained biochar, raises the question of

72 whether biochar influences the type and extent of the hydration reactions or causes

73 microstructural and textural changes that favor strength development. This paper

74 addresses the mechanisms by which biochar affects strength development.

75 The mineralogy, texture and microstructure of mixtures of $1000 \%$ water content peat,

76 OPC and different particle-size biochar filler were characterized by Scanning Electron

77 Microscopy (SEM), combined with Energy-Dispersive X-ray Spectroscopy (EDS), and

78 Powder X-Ray Diffraction (XRD). The same samples that were used for UCS testing by

79 Lau et al. (2019) were investigated after seven days of curing. The peat-OPC-biochar 
mixture prepared with biochar size below $75 \mu \mathrm{m}$, was further tested at 28 and 120 days by XRD to investigate potential changes in hydration products and the progression of the hydration reaction. The results of this study provide the groundwork for the long-term prediction of the cement stabilized soil strength and of the effects of large-scale use.

\section{MATERIALS AND METHODS}

\section{Preparation of Peat, OPC, Biochar Mixtures}

Five mixtures of peat-biochar-cement, differing only in the grain size of biochar, and a control sample consisting of peat and cement were investigated in this study. The peat was reconstituted to a water content of $1000 \%$. This value falls into the middle of the natural water content range of peat soils, according to a review by Huat (2004). The source and preparation of peat and cement is described in detail in the paper by Lau et al. (2019) and is summarized here. Peat, sourced from Irish bogs owned by the Bord na Mona company, was obtained from a local garden center. It is a brown peat, with moderately strong humification, corresponding to the H6 class of the von Post scale (Hartlén and Wolski 1996). The peat has low fiber content, zero tensile strength, and a $\mathrm{pH}$ of 3.6. The peat purchased for this study had been previously dried thus its natural water content is not known. Bags of peat were mixed thoroughly in bulk to ensure homogeneity and sieved to remove debris larger than $5 \mathrm{~mm}$. Tap water was added to the peat and mixed in a paint paddle mixer until a water content of $1000 \%$ was reached. The reconstituted peat had a bulk density of $976 \mathrm{~kg} / \mathrm{m}^{3}$. The biochar, produced by BioRegional, was derived 
100 from sustainably sourced timber wood chips pyrolyzed at $450^{\circ} \mathrm{C}$ for 48 hours. It was 101 graded into five different particle size ranges, named A to E, from the coarsest (5-2 mm 102 range) to the finest $(<75 \mu \mathrm{m})$, to yield five differently graded mixtures, as shown in Table 103 1. Biochar was dried in the oven at $50^{\circ} \mathrm{C}$ for 24 hours to remove moisture while preserving 104 the integrity of its micropores, prior to mixing with the peat. The $\mathrm{pH}$ of biochar, measured 105 after dilution with distilled water, was 8.1.

106 Mixtures were prepared starting with the reconstituted peat, by adding $20 \%$ by weight 107 of biochar and $20 \%$ by weight of OPC. Biochar and OPC were added sequentially, each 108 addition followed by mixing for 5 minutes at medium speed. The mixture was then 109 spooned into lightly greased, $70 \mathrm{~mm}$ PVC split molds in five layers. After each of the 5 110 layers, the mixture was pushed down gently using a fork and tamped 10 times, with a $11130 \mathrm{~mm}$ diameter cylindrical aluminum rod. The samples were left to cure in a large tank 112 filled with water halfway up the sides of the molds, allowing water to flow in. All 113 specimens were cured for 7 and 28 days; a few specimens cured for up to 120 days.

114 Unconfined compressive strength tests were conducted according to ASTM D2166 115 (ASTM, 2013). Triplicate specimens were run after 7 and 28 days for all samples. Analytical Methods

117 Samples were analyzed by Scanning Electron Microscopy (SEM), with a 118 Thermofisher/FEI Quanta 600, equipped with a dedicated solid state backscatter detector 119 and a Bruker silicon drift detector (SDD) for Energy Dispersive X-ray Spectroscopy (EDS) 
120 of elements with atomic number higher than B. After 7 days of curing, a set of samples

121 was air dried and coated with $\mathrm{Pt} / \mathrm{Pd}$, to limit charging, while another set was dehydrated

122 by methanol exchange, embedded in Spurr epoxy resin (modified according to Ellis,

123 2006), polished down to $0.5 \mu \mathrm{m}$, and coated with $\mathrm{Pt} / \mathrm{Pd}$. Air dried samples were analyzed

124 in secondary mode (SE) at $10 \mathrm{keV}$ to observe the morphology of the grains and

125 components of the mixture. In secondary mode, image contrast is mainly a function of

126 topography. Polished samples were instead analyzed in backscatter mode (BSE) which

127 gives micrographs where gray contrast is a function of average atomic number of the

128 material, with higher contrast corresponding to higher atomic number. EDS spectra were

129 collected by point analysis from the polished blocks, and a few from particles in the air-

130 dried samples. An operating voltage of $20 \mathrm{keV}$ was used for EDS microanalysis.

131 Mineral composition of samples cured for 7 days was analyzed by powder X-ray

132 diffraction $(\mathrm{XRD})$, with a Siemens D500 diffractometer, using $\mathrm{Cu}-\mathrm{k} \alpha$ radiation and

133 operated at $40 \mathrm{kV}$ and $40 \mathrm{~mA}$. Samples were scanned between 3 and $65^{\circ} 2 \theta$, at steps of

$134 \quad 0.05^{\circ} 2 \theta$ and $4 \mathrm{sec} / \mathrm{step}$ counting time. Additional XRD were acquired from samples $\mathrm{A}$ and

135 E after 28 days of curing and on sample E after 120 days, by a Bruker D8 Advance

136 diffractometer, using $\mathrm{Cu}-\mathrm{k} \alpha$ radiation, and operated at $40 \mathrm{kV}$ and $40 \mathrm{~mA}$, using the

137 same acquisition settings.

138 Phase quantification for the crystalline fraction was computed by Rietveld analysis

139 using the program BGMN (Taut, Kleeberg and Bergmann 1998), accessed through the 
140 Profex graphical interface (Döbelin and Kleeberg 2015). The program BGMN-Profex

141 models mineral peaks in the XRD pattern by deconvolution of the wavelength

142 distribution over the 2-theta range, the instrument profile and the mineral structure

143 parameters (Taut, et al., 1998). Rietveld refinement accounts for variations in mineral

144 composition on peak position, as well as the effect of small size and strain on peak shape

145 and area. Therefore, it is an ideal choice to quantify cement hydration products.

\section{RESULTS AND DISCUSSION}

\section{Unconfined Compressive Strength (UCS)}

148 The effects of biochar addition and biochar size on UCS of cement stabilized peat soil

149 were compared to sand fillers (Fig. 1). The increase in UCS strength associated with

150 biochar filler is comparable to that associated with sand. Most importantly, for biochar size

151 smaller than $75 \mu \mathrm{m}$, cement stabilized peat UCS surpasses that of coarser biochar size filler

152 by $170 \%$ and that of same grain-size sand by $35 \%$. Fig. 1 shows that the biochar size effect

153 starts in the early stages of hydration: it is already evident at 7 days. After 28 days, a peak

154 in UCS strength is evident for the fine-size biochar. This is an unexpected result.

155 Unconfined compressive strength in these mixes is due to the presence of cement that

156 allows bonding of particles. Inert fillers add particles that the cement can bind to and

157 together they create a stronger and stiffer structure within the matrix material. All

158 specimens have equal amount by weight of cement, peat and either sand or biochar. Sand

159 grains are harder than biochar, with reported hardness values of $10 \mathrm{GPa}$ and $3 \mathrm{GPa}$, 
160 respectively (Daphalapurkar, et al. 2010, Dixit, et al. 2019). In the composite material, we

161 expect failure surfaces to seek weak bonds, with less cement, or go through areas with a

162 less favorable distribution of cement. The relative greater hardness of sand grains than

163 biochar seems to favor sand because failure could occur through biochar grains whereas

164 it will always go around sand grains. This mechanism could explain the slightly higher

165 UCS associated with a sand filler for samples A to D. However, it does not explain the

166 higher strength of sample E with biochar filler of the finest size. Smaller particles appear

167 to provide a more uniformly distributed network to support the cement bonds, leaving

168 fewer weak uncemented spots, as both fine sand and fine biochar result in higher

169 strengths. However, this mechanistic interpretation cannot fully explain the large

170 difference between the two materials in favor of biochar.

171 As a porous material, biochar absorbs some water, but the overall availability for the

172 cement hydration reactions is far in excess of the optimum water/cement ratio. The water

173 content of all sand specimens at 28 days is in excess of $130 \%$ with higher values $(>150 \%)$

174 for the biochar specimens. The intra-group difference is minimal in each set, where

175 specimens A-D have nearly the same water content as specimen E.

176 Scanning Electron Microscopy

177 Our characterization of peat-biochar-OPC mixtures, at 7 days of hydration, is based on

178 the analysis of over 90 SEM-SE micrographs from air-dried samples, more than 140 SEM-

179 BSE micrographs (atomic contrast) from embedded-polished blocks and over 200 EDS 
spectra.

Analysis by SEM reveals the presence of calcium silicate hydrate (C-S-H) and ettringite needles in all samples (Fig. 2). C-S-H gel, easily identifiable from its sponge-like texture, completely covers the grains whereas ettringite needles, up to $10 \mu \mathrm{m}$ in length, protrude from the gel. EDS analysis from a rectangular region of the coating (C 34 in Fig. 2) shows $\mathrm{O}, \mathrm{Ca}$ and $\mathrm{Si}$, with lesser fraction of $\mathrm{Al}$ and traces of $\mathrm{Mg}$ which is consistent with the chemical composition of C-S-H (Richardson 2008, L'Hôpital, et al. 2015). Similarly, EDS from the needles (Point C33 in Fig. 2) shows the presence of $\mathrm{O}, \mathrm{Ca}, \mathrm{Al}$ and $\mathrm{S}$, consistent with ettringite, the most common sulfoaluminate phase (AFt). C-S-H and ettringite are two major products of the early stages of cement hydration that form from the reaction of tricalcium silicate $\left(\mathrm{C}_{3} \mathrm{~S}\right)$, calcium aluminate $\left(\mathrm{C}_{3} \mathrm{~A}\right)$ and gypsum with water.

Fragments of biochar are identified in SEM micrographs by their rigid, open cellular structure, composed of a bundle of sub-prismatic cells, separated by solid walls (Fig. 3A, B). Measurements taken from polished sections (Fig.3-C) indicate that wall thickness ranges between 1 and $3 \mu \mathrm{m}$, cell width between 7 and $10 \mu \mathrm{m}$ and cell length between 20 and $40 \mu \mathrm{m}$. Fig. 3-A, B show the typical appearance of a biochar fragment after one week of curing, with its surface covered by hydration products. C-S-H coating grows with a sponge-like appearance on the surface and ettringite needles fill the cells, to varying extent. Polished cross sections of the biochar, analyzed in backscatter mode (Fig. 3-C), further show that filling of the cells is complete in the outer portion of the biochar and 
200 decreases inward, with the innermost cells remaining void, or partially covered by a thin

201 layer of C-S-H. The composition of the filling also undergoes some changes as portlandite

202 ( $\mathrm{CH}$ in cement notation) and other $\mathrm{Ca}$ compounds are only found in the outer cells,

203 whereas C-S-H tends to penetrate further inward (Fig. 3-C). For samples A to D, biochar

204 fragments still preserve their internal, cellular structure (Fig. S-1). Sample E, where

205 biochar size is smaller than $75 \mu \mathrm{m}$, is the exception, as most fragments are too small to

206 show any relict internal cells (Fig. S-1). Instead, biochar pieces appear as rigid particles

207 with complex, jagged shape and large, exposed surface area but no preserved internal

208 macro-pores.

209 Although peat fragments are heterogeneous in shape and size, they are always orders

210 of magnitude larger than cement particles and larger than biochar fragments. Like

211 biochar, many peat fragments show internal cells but, in contrast to biochar, peat

212 fragments are flexible, they look bent and deformed. In fact, many peat fragments appear

213 as porous ribbons that wrap cement and hydration products (Fig. 4). BSE micrographs

214 show that peat is commonly associated with larger voids and more porosity, distributed

215 both inside the peat (intraporosity) and between peat fragments.

216 In some instances (Fig. 4-D, Fig. S-2), cells within the peat show varying degrees of

217 filling by $\mathrm{Ca}-\mathrm{Al}$ rich minerals and $\mathrm{Ca}-\mathrm{Al}$ minerals with minor Si and $\mathrm{S}$, as determined by

218 EDS.

219 In samples $\mathrm{C}, \mathrm{D}$, and $\mathrm{E}$ microcrystalline, microporous aggregates of calcite $\left(\mathrm{CaCO}_{3}\right), 5$ 
220 to $20 \mu \mathrm{m}$ in size are found, most frequently filling the outer cells of biochar, rarely outside

221 biochar fragments (Fig. 5).

222 The microcrystals are assembled in tight cubic grains that show growing bands in BSE

223 (Fig. 6), a clear evidence that they grew in situ. EDS analysis cannot effectively

224 differentiate portlandite and calcite. However, these two minerals have significantly

225 different average atomic number (calcite 12.56 and portlandite 14.3 ) because of their

226 different crystal structure, that results in different backscattered absorption coefficients

227 (calcite: 0.142, portlandite: 0.162) therefore different contrast in BSE micrographs

228 (Stutzman 2004). The difference in contrast was clear in our BSE analysis.

229 Mineralogy after at 7 Days of Curing by XRD

230 The 7 days XRD patterns of the mixtures with five different grain size of biochar and

231 the control sample show reflections at similar 2-theta angles and overall similar features.

232 The presence of peat contributes a diffuse reflection and also attenuates the reflection of

233 other minerals, adding complexity to the pattern (Fig. 7). Biochar fibers are composed of

234 both crystalline and amorphous material, with a degree of crystallinity reported in the

235 literature on the order of $40-60 \%$ (Borrega, et al. 2015). Biochar crystalline component is

236 primarily cellulose and is observed in the XRD pattern by its reflection at $22.9^{\circ} 2 \theta$.

237 Portlandite, calcite and $\mathrm{C}_{2} \mathrm{~S}$ (larnite) account for the most intense and narrow peaks in the

238 XRD pattern (Fig. 7), indicating that these are the most abundant crystalline components

239 of the mixture. $\mathrm{C}_{2} \mathrm{~S}$ is a slow reacting clinker component that contributes to the long -term 
240 strength of the cement and is expected to be found after 7 days. In contrast, the fast

241 reacting components of the clinker, gypsum, tricalcium silicate $\left(\mathrm{C}_{3} \mathrm{~S}\right)$, and calcium

242 aluminate $\left(\mathrm{C}_{3} \mathrm{~A}\right)$, were not detected either by XRD or SEM, indicating that the initial phase

243 of OPC hydration had completed.

$244 \mathrm{CH}, \mathrm{C}-\mathrm{S}-\mathrm{H}$ and ettringite are the main products of hydration and among them, only

$245 \mathrm{CH}$ forms well developed crystals that yield clear peaks in the diffraction pattern.

246 Ettringite peaks are commonly identified in XRD patterns (Hernandez-Martinez 2006),

247 but are not visible in the XRD patterns of these samples, at 7 days or even at 28 days.

248 Nonetheless, needles with the morphology and chemical composition of ettringite were

249 observed by SEM, in all samples. The absence of peaks in the XRD pattern may be due to

250 the attenuating effect of peat, in combination with a low degree of crystallinity of

251 ettringite. C-S-H make up the main binding agent during the early hydration stage but

252 they are difficult to characterize and identify because their composition is variable and

253 they are generally poorly crystalline (Richardson 2008, Lothenbach and Winnefeld 2006).

254 The experimental diffraction patterns at 7 days show broad reflections on the shoulder

255 of $\mathrm{C}_{2} \mathrm{~S}$ peaks that can be attributed to $\mathrm{C}-\mathrm{S}-\mathrm{H}$ and specifically to rosenhanite $\left(\mathrm{C}_{3} \mathrm{~S}_{3} \mathrm{H}\right)$ and

256 dellaite $\left(\mathrm{C}_{6} \mathrm{~S}_{3} \mathrm{H}\right)$, depending on sample (Fig. 8).

257 The presence of calcite detected by XRD, and confirmed by SEM-BSE micrographs

258 (Fig. 5), is evidence that, in addition to the hydration reactions that lead to formation of

$259 \mathrm{CH}$ and $\mathrm{C}-\mathrm{S}-\mathrm{H}$, carbonation also takes place. The carbonation reaction occurs when $\mathrm{CO}_{2}$ 
260 diffuses into pore water and forms carbonic acid $\left(\mathrm{H}_{2} \mathrm{CO}_{3}\right)$ which, in turn, dissociates into

261 bicarbonate ion $\left(\mathrm{HCO}_{3}^{-}\right)$, and carbonate ion $\left(\mathrm{CO}_{3}^{2-}\right)$ causing the $\mathrm{pH}$ to decrease (Cizer, et

262 al. 2012). The lower $\mathrm{pH}$ drives the reaction of portlandite with the carbonate ions in

263 solution to form calcite and water, according to Eq. 1 (Johannesson and Utgenannt 2001,

264 Cizer, et al. 2012, Frías and Goñi 2013, Shi, et al. 2016):

$$
\mathrm{Ca}(\mathrm{OH})_{2}+\mathrm{CO}_{3}^{2-} \rightarrow \mathrm{CaCO}_{3}+\mathrm{H}_{2} \mathrm{O}
$$

265 The carbonation reaction in concrete is diffusion limited, it only occurs on surfaces exposed to a source of $\mathrm{CO}_{2}$ (Haselbach 2009). Labile Carbon in peat is one source that has

267 been shown to promote the carbonation reaction (Duggan, et al. 2019). SEM analysis 268 demonstrate that another important source is biochar.

269 While it is considered inert, research shows that a transient flux of $\mathrm{CO}_{2}$ can be released 270 by biochar within the first few days to weeks after addition to soils (Cardelli, et al. 2016,

271 Bruun, et al. 2014). It is quite likely that a similar release occurs from the surface of the

272 biochar mixed to cement. Experimental studies show that carbonation of portlandite has 273 negligible effect on $\mathrm{pH}$ (Shi, et al. 2016) because it is a surface process that proceeds only 274 as deep as the reach of the diffusion of $\mathrm{CO}_{2}$ and has a positive effect on strength, as long 275 as the distribution of calcite is homogeneous (Cizer, et al. 2012). Negative effects on 276 strength are possible when a carbonation front develops, as for $\mathrm{CO}_{2}$ injection, leading to 277 localized micro-crack formation (Fabbri, et al. 2009). This is not the case for our samples 278 where instead biochar is homogeneously mixed with the peat and cement. Therefore, any 
279 release of $\mathrm{CO}_{2}$ from biochar surface, is also randomly distributed within the sample.

280 Another region of interest in the XRD pattern is between $6-25^{\circ} 2 \theta$ (Fig. 9). A diffuse

281 but clear reflection occurs at a 2-theta angle of $\sim 19^{\circ}$, in all samples that contain biochar.

282 This peak indicates the presence of an AFm phase, a group hydrated layered calcium

283 aluminate with general composition of $\mathrm{Al}_{2} \mathrm{O}_{3}-\mathrm{Fe}_{2} \mathrm{O}_{3}-\mathrm{X}$, where $\mathrm{X}$ indicates a monocharge

284 anion like $\mathrm{OH}^{-}$, or half of a doubly charged anion like $\mathrm{SO}_{4}^{2-}, \mathrm{CO}_{3}^{2-}$ (Matschei, Lothenbach

285 and Glasser 2007). AFm phases can form from the hydration of $\mathrm{C}_{3} \mathrm{~A}, \mathrm{C}_{4} \mathrm{AF}$ or conversion

286 of ettringite and C-S-H. The peaks in the XRD pattern can be attributed to

287 monocarboaluminate, a phase that forms when excess $\mathrm{Al}$ and $\mathrm{Ca}$ occur with respect to

288 sulfate (Bonavetti, Rahhal and Irassar 2001, Ipavec, et al. 2011).

289 Accordingly, calcite and carbonate ions favor the formation of monocarboaluminate,

290 as well as the transient hemicarboaluminate (Ipavec, et al. 2011, Mohamed, et al., 2015).

291 Thermodynamic modeling of cement hydration shows that monocarboaluminate is the

292 most stable form of AFm (Lothenbach and Winnefeld 2006).

293 Early studies on the effect of monocarboaluminate on mechanical properties found

294 that its formation did not negatively affect the strength, compared to other AFm phases

295 (Fernández, et al., 2018, Lothenbach, et al. 2008). Moon et al. (2014) found a dependence

296 between compressibility of monocarboaluminate with number of layers of water in the

297 interlayer of the structure.

Berti, February 8, 

shows the experimental diffraction pattern (black) and the simulated pattern (magenta)

301 based the on the minerals identified. The bottom plot shows the difference between the 302 experimental and simulated profiles. Simulation of mineral XRD patterns is based on 303 atomic structure models taken either from the ICDD pdf-4 mineral database (Kabekkod 304 2016) or from the Crystallography Open Database (Grazulis, et al. 2012). The shape of mineral peaks is modified by variables that depend on instrument settings, crystallite size 306 and mineral abundance. Cellulose is included in the mixture because it is a crystalline 307 component of biochar that can be identified in the experimental patterns. Table 2 lists the 308 mineral models used, and the results of the quantification, normalized to the crystalline 309 fraction of the mixture.

310 Table 2 groups clinker components and hydration products. Peat and biochar 311 contribute a diffuse reflection that is added to the background. It is evident, from the 312 quantification results, that the extent of hydration at 7 days, indicated by the sum of all 313 hydration products, is similar in all samples (Fig. 11). The composition of the hydrated 314 products however, changes between the control sample and the samples with biochar 315 filler. Calcite, while present in all samples, is far more abundant in samples with biochar, 316 a confirmation that carbonation occurs in OPC stabilized peat and is promoted by 317 biochar. Further, an inverse trend between the concentration of calcite and portlandite, 
318 indicates carbonation of the latter.

319 Monocarboaluminate is another mineral that shows a significant variation in

320 abundance between the control sample, where it is not detected, and the samples with

321 biochar filler, containing 5 to $9 \%$. While there is no obvious trend, sample E, with the

322 finest grain size, contains the largest fraction.

323 Mineralogy Changes Over Time

324 Diffraction patterns collected after 28 days of hydration from samples A and E, the two 325 end members of biochar grain size subdivisions, show identical features (Fig. 12). The 326 similarity in mineralogy is evidence that the hydration reaction proceeds towards the 327 same end composition over time, in all samples with biochar filler. Size, therefore, is 328 important in the early stages when hydrated minerals nucleate on the surface of biochar.

329 This result is consistent with research by Dixit et al. (2019) who observed an acceleration

330 of the hydration reaction after adding fine-size $(<150 \mu \mathrm{m})$ biochar to OPC. Dixit et al. 331 (2019) found that coarser-size biochar promoted hydration in later stages, due to slow 332 moisture release. Not surprisingly, this is not the case in our study where specimens 333 could take in water, during curing.

334 The long-term trend of the mineralogy of the OPC stabilized samples with filler was 335 assessed from sample E, by quantitative mineral analysis at 7, 28 and 120 days. Mineral 336 quantification, normalized to the crystalline fraction, is shown in Table 3 while the bar 337 diagrams in Fig. 12 display the trend of the hydrated minerals. The results show that 
monocarboaluminate persists in the long terms, and its concentration increases over time.

339 Further, the full-width at half maximum of this mineral XRD peak becomes narrower,

340 indicating an increase in the size of diffracting domain -that reflects larger and more

341 ordered crystals. Notably, the content of calcite also shows a distinct increase over time,

342 up to $40 \%$ of the mineral fraction. This further confirms that carbonation contributes to

343 the increase in strength of the material.

344 Portlandite concentration also increases in the long term. However, it suffers a

345 transient decrease in concentration at 28 days, concomitant with the occurrence of two

346 calcium oxalate salts (Ca-oxalate and Ca-oxalate hydrate). These salts, that give sharp

347 peaks in the XRD pattern at $13,14,19^{\circ} 2 \theta$ (Fig. 12), precipitate from humic acids in the

348 presence of excess calcium (Franceschi and Nakata 2005). Likely, the excess calcium is

349 released by dissolution of portlandite whereas humic acids derive from the peat, biochar,

350 or both. Such dissolution can occur from a local lowering of the $\mathrm{pH}$ associated with the

351 progression of the carbonation reaction (Johannesson and Utgenannt 2001).

352 In mixtures, Ca-oxalate is, however, a transient phase that is fully consumed between

35328 and 120 days. In fact, the diffraction pattern of sample E, after 120 days of hydration,

354 does not show any Ca-oxalate peaks (Fig. 12). Rather, the concentration of portlandite

355 increases from approximately $6 \%$ to $23 \%$ between 28 and 120 days, raising above the 7

356 days concentration (Fig. 13). Calcite concentration decreases slightly from $39 \%$ to $32 \%$

357 while C-S-H concentration increases but at slower pace than in the first 7 days. During 
358 the same time, the abundance of the unreacted clinker $\left(\mathrm{C}_{2} \mathrm{~S}\right)$ decreases from

359 approximately $24 \%$ to $16 \%$ (Table 3). Clearly, over time, the remaining clinker

360 components in OPC hydrate, buffering any local change in $\mathrm{pH}$, and yield mineral phases

361 that add strength to the peat. In fact, UCS tests show calcite, portlandite and

362 monocarboaluminate are the minerals that contribute to the overall strength.

363 Texture and Microstructure

364 SEM-BSE micrographs of the control sample, which is solely composed of peat and

365 OPC, show clusters composed of a core of unreacted $\mathrm{C}_{4} \mathrm{AF}$ and $\mathrm{C}_{2} \mathrm{~S}$, with sub-round shape

366 and average size of $25 \mu \mathrm{m}$ that is surrounded by C-S-H gel and ettringite. These clusters

367 are dispersed in the matrix, with relatively homogeneous distribution (Fig. 14 A, B). Peat

368 fragments with heterogeneous morphology and size also show a relatively homogeneous

369 spatial distribution. Void space is still dominant after one week. In fact, measurements

370 from image analysis of BSE micrographs show that at least $50 \%$ of the area fraction is

371 void space, with the largest voids found in peat chambers and along the rim of peat

372 fragments (Fig. 14-B). As the clusters of cement and hydration products grow, they fill in

373 the void space, displace and deform the peat. The size of clusters and their hydration

374 shells vary by location, indicating local variability in extent of hydration, at this stage.

375 With the addition of biochar, hydration of cement not only occurs in clusters located

376 in the void space of the mixture, but also, and more importantly, on the external surface

377 and cells of biochar. Fig. 3 showed that the biochar surface catalyzes the nucleation of C- 
S-H and AFm phases. BSE micrographs show a rind of cementitious gels at the outer edge of large biochar fragments (Fig. 14-C, D) and the edges of fine fragments (Fig. 14-E). Coated biochar edges appear brighter. BSE micrographs further show that hydration products do not reach the inner cells of large biochar fragments, likely because the newly formed hydration products tend to occlude pores and pore throats. In contrast to peat, biochar fragments are rigid therefore offer higher resistance to deformation, leading to an increase in strength of the overall mixture.

At this early stage however, rigid biochar bodies are still separated by large void space that provides weak zones where fractures can develop and grow. In larger fragments (Fig. 14-C, D) weak surfaces are also larger. Further, in samples A through D it is common to observe clusters of biochar fragments partially cemented together (Fig. 14-D) creating even larger weak surfaces around them. However, fragments of biochar that are sufficiently small to be comparable to the size of unhydrated cement grain, like in sample E, result in a homogeneous size distribution of the rigid grains in the mixture. In turn, the distribution of the granular, rigid material is also more homogeneous and less likely to favor development of weak surfaces.

Because the exposed surface of biochar promotes nucleation of hydrated products, a more homogeneous distribution of biochar also corresponds to a better distribution of hydration products. This better distribution is apparent in BSE micrographs from a comparison of samples with coarse fragments of biochar (Fig. 14-C, D) with sample E 
398 (Fig. 14-E, F). According to this hypothesis, as hydration progresses, the new hydrated

399 minerals will progressively fill the void space, deform and compress the peat, ultimately

400 yielding a more continuous grain framework with more points of contact between

401 particles, aggregates and biochar fragments.

402 CONCLUSIONS

403 As sand becomes less available and more expensive, alternatives that are both 404 sustainable and environmentally friendly are highly desirable. Biochar, the carbon 405 negative product of pyrolysis, has been shown as a viable option to replace sand fillers in 406 OPC stabilized peat soils (Lau et al., 2019). This paper investigated the mechanisms by 407 which the addition of biochar contributes to the development of strength. Mineral, 408 textural and microstructural characterization of cement stabilized peat soil samples with 409 biochar filler demonstrated that 1) biochar catalyzes the nucleation of hydration minerals 410 on its surface. 2) It favors hydration reactions that encourage the formation of minerals 411 that add strength to the peat, in the short and long term. 3) Biochar counteracts the 412 negative effects of peat on cement hydration. 4) Similarly to sand filler, the microstructure 413 of the peat soil is improved by addition of rigid grains to an otherwise soft and easily 414 deformable material. 5) A particle size smaller than $75 \mu \mathrm{m}$ results in better filling of the 415 space by biochar. In turn, the more biochar surface becomes available to growth of 416 hydration products, promoting faster rate of unconfined compressive strength increase 417 in the early stages. Lastly, biochar favors the carbonation reaction, which contributes to 
418 store carbon in a recalcitrant form.

419 Data Availability Statement

420 Some or all data, models, or code that support the findings of this study are available

421 from the corresponding author upon reasonable request.

422 Acknowledgments

423 The authors thank three anonymous reviewers for their insightful and constructive

424 comments. This work used shared facilities at the Virginia Tech National Center for Earth

425 and Environmental Nanotechnology Infrastructure (NanoEarth), a member of the

426 National Nanotechnology Coordinated Infrastructure (NNCI), supported by NSF (ECCS

427 1542100).

428 REFERENCES

429 ASTM 2013. Standard test method for unconfined compressive strength of cohesive soil. ASTM

430 D2166. West Conshohocken, PA: ASTM.

431 Bonavetti, V. L., V. F. Rahhal, and E. F. Irassar. 2001. "Studies on the carboaluminate formation

432 in limestone filler-blended cements." Cement and Concrete Research 31: 853-859.

433 doi:10.1016/S0008-8846(01)00491-4.

434 Borrega, M., P. Ahvenainen, R. Serimaa, and L. J. Gibson. 2015. "Composition and structure of 435 balsa (Ochroma pyramidale) wood." Wood Science and Technology 49: 403-420.

436 doi:10.1007/s00226-015-0700-5.

437 Bruun, S., S. Clauson-Kaas, L. Bobul'ská, and I. K. Thomsen. 2014. "Carbon dioxide emissions

438 from biochar in soil: role of clay, microorganisms and carbonates." European Journal of Soil 
Science 65: 52-59. doi:10.1111/ejss.12073.

440 Cardelli, R., M. Becagli, F. Marchini, A. Saviozzi, and M. Goss. 2016. "Short-term releases of CO2

441 from newly mixed biochar and calcareous soil." Soil use and Management 32: 543-545.

442 Cizer, Özlem, Carlos Rodriguez-Navarro, Encarnación Ruiz-Agudo, Jan Elsen, Dionys Van

443 Gemert, and Koenraad Van Balen. 2012. "Phase and morphology evolution of calcium

444 carbonate precipitated by carbonation of hydrated lime." Journal of Materials Science 47: 6151-

$445 \quad$ 6165. doi:10.1007/s10853-012-6535-7.

446 Daphalapurkar, N. P., F. Wang, B. Fu, H. Lu, and R. Komanduri. 2010. "Determination of

447 Mechanical Properties of Sand Grains by Nanoindentation." Experimental Mechanics (Springer

448 Science and Business Media LLC) 51: 719-728. doi:10.1007/s11340-010-9373-z.

449 Dixit, Anjaneya, Souradeep Gupta, Sze Dai Pang, and Harn Wei Kua. 2019. "Waste Valorisation

450 using biochar for cement replacement and internal curing in ultra-high performance

451 concrete." Journal of Cleaner Production 238: 117876. doi:10.1016/j.jclepro.2019.117876.

452 Döbelin, N., and R. Kleeberg. 2015. "Profex: a graphical user interface for the Rietveld

453 refinement program BGMN." Journal of Applied Crystallography 48: 1573-1580.

454 doi:10.1107/s1600576715014685.

455 Duggan, Alan R., Bryan A. McCabe, Jamie Goggins, and Eoghan Clifford. 2019. "Evidence of 456 Stabilized Peat as a Net Carbon Sink." Journal of Materials in Civil Engineering 31: 04019005. 457 doi:10.1061/(asce)mt.1943-5533.0002605.

458 Ellis, E. A. 2006. "Solutions to the problem of substitution of ERL 4221 for vinyk cyclohexene 459 dioxide in Spurr low viscosity embedding formulations." Microscopy Today 14: 32-33.

$460 \quad$ doi:10.1017/S1551929500050252. 
461 Fabbri, A., J. Corvisier, A. Schubnel, F. Brunet, B. Goffé, G. Rimele, and V. Barlet-Gouédard.

462 2009. "Effect of carbonation on the hydro-mechanical properties of Portland cements." Cement

463 and Concrete Research 39: 1156-1163. doi:10.1016/j.cemconres.2009.07.028.

464 Fernández, A., G. Calvo, and M. C. Alonso. 2018. "Ordinary Portland Cement composition for

465 the optimization of the synergies of supplementary cementitious materials of ternary binders

466 in hydration processes." Cement and Concrete Composites 89: 238-250.

467 doi:10.1016/j.cemconcomp.2017.12.016.

468 Franceschi, V., and P. Nakata. 2005. "CALCIUM OXALATE IN PLANTS: Formation and

469 Function." Annual Review of Plant Biology 56: 41-71.

470 doi:10.1146/annurev.arplant.56.032604.144106.

471 Frías, Moisés, and Sara Goñi. 2013. "Accelerated carbonation effect on behaviour of ternary

$472 \quad$ Portland cements." Composites Part B: Engineering 48: 122-128.

473 doi:10.1016/j.compositesb.2012.12.008.

474 Gibson, L. J. 2003. "Cellular Solids." MRS Bulletin (Cambridge University Press (CUP)) 28: 270-

$475 \quad$ 274. doi:10.1557/mrs2003.79.

476 Grazulis, S., A. Daskevič, A. Merkys, D. Chateigner, L. Lutterotti, M. Quirós, N. R.

477 Serebryanaya, P. Moeck, R. T. Downs, and A. Le Bail. 2012. "Crystallography Open Database

478 (COD): an open-access collection of crystal structures and platform for world-wide

479 collaboration." Nucleic Acids Research 40: D420-D427. doi:10.1093/nar/gkr900.

480 Gupta, Souradeep, and Harn Wei Kua. 2017. "Factors Determining the Potential of Biochar As a

481 Carbon Capturing and Sequestering Construction Material: Critical Review." Journal of

482 Materials in Civil Engineering 29: 04017086. doi:10.1061/(ASCE)MT.1943-5533.0001924.

Berti, February 8, 
483 Gupta, Souradeep, Harn Wei Kua, and Hui Jun Koh. 2018. "Application of biochar from food 484 and wood waste as green admixture for cement mortar." Science of The Total Environment 619485 620: 419-435. doi:10.1016/j.scitotenv.2017.11.044.

486 Hartlén, J., and W. Wolski. 1996. Embankments on organic soils. doi:10.1016/s0165-1250(96)800034874.

488 Haselbach, Liv. 2009. "Potential for Carbon Dioxide Absorption in Concrete." Journal of 489 Environmental Engineering 135: 465-472. doi:10.1061/(asce)ee.1943-7870.0000004.

490 Hernandez-Martinez, F.-G. 2006. "Ground Improvement of Organic Soils Using Wet Deep Soil 491 Mixing." Ph.D. dissertation, Engineering Department, Cambridge University, UK, 331. 492 doi:10.1016/b978-0-12-408076-8.00006-6.

493 Ipavec, A., R. Gabrovšek, T. Vuk, V. Kaučič, J. Maček, and A. Meden. 2011. "Carboaluminate 494 Phases Formation During the Hydration of Calcite-Containing Portland Cement." Journal of the 495 American Ceramic Society 94: 1238-1242. doi:10.1111/j.1551-2916.2010.04201.x.

496 Janz, M., and S.-E. Johansson. 2002. "The Function of Different Binding Agents in Deep 497 Stabilisation, Report 9." The Function of Different Binding Agents in Deep Stabilisation, Report 9. 498 Swedish Deep Stabilization Research Centre. 1-50.

499 Johannesson, Björn, and Peter Utgenannt. 2001. "Microstructural changes caused by carbonation $500 \quad$ of cement mortar." Cement and Concrete Research 31: 925-931. doi:10.1016/S0008-8846(01)00498$501 \quad 7$.

502 Kabekkod, Soorya, ed. 2016. "PDF-4+ 2016." PDF-4+ 2016. ICDD (International Centre for 503 Diffraction Data). doi:10.18411/d-2016-154.

504 Larson, C. 2018. "Asia's hunger for sand takes toll on ecology." Science 359: 964-965. 
doi:10.1126/science.359.6379.964.

506 Lau, J., G. Biscontin, and D. Berti. 2019. "Effects of biochar on cement stabilised peat soil."

507 Proceedings of the Institution of Civil Engineers Ground Improvement 1-12.

508 doi:10.1680/jgrim.19.00013.

509 Lehmann, J., and S. Joseph, . 2015. Biochar for Environmental Management. Taylor \& Francis.

$510 \quad$ doi: $10.4324 / 9780203762264$

511 L'Hôpital, E., B. Lothenbach, G. Le Saout, D. Kulik, and K. Scrivener. 2015. "Incorporation of

512 aluminium in calcium-silicate-hydrates." Cement and Concrete Research 75: 91-103.

513 doi:10.1016/j.cemconres.2015.04.007.

514 Lothenbach, B., and F. Winnefeld. 2006. "Thermodynamic modelling of the hydration of

515 Portland cement." Cement and Concrete Research 36: 209-226.

516 doi:10.1016/j.cemconres.2005.03.001.

517 Lothenbach, B., G. Le Saout, E. Gallucci, and K. Scrivener. 2008. "Influence of limestone on the

518 hydration of Portland cements." Cement and Concrete Research 38: 848-860.

519 doi:10.1016/j.cemconres.2008.01.002.

520 Matschei, T., B. Lothenbach, and F. P. Glasser. 2007. "The AFm phase in Portland cement."

521 Cement and Concrete Research 37: 118-130. doi:10.1016/j.cemconres.2006.10.010.

522 Mohamed, Ashraf Ragab, Mona Elsalamawy, and Marwa Ragab. 2015. "Modeling the influence

523 of limestone addition on cement hydration." Alexandria Engineering Journal 54: 1-5.

$524 \quad$ doi:10.1016/j.aej.2014.11.004.

525 Moon, J., S. Yoon, R. M. Wentzcovitch, and P. J. M. Monteiro. 2014. "First-principles elasticity of 526 monocarboaluminate hydrates." American Mineralogist 99: 1360-1368.

Berti, February 8, 
doi:10.2138/am.2014.4597.

528 Osman, K. T. 2018. "Management of soil problems." Chap. Peat Soils, 145-183. doi:10.1007/978-3-

529 319-75527-4_1.

530 Park, J. H., G. k. Choppala, N. S. Bolan, J. W. Chung, and T. Chuasavathi. 2011. "Biochar reduces

531 the bioavailability and phytotoxicity of heavy metals." Plant and Soil 348: 439-451.

532 doi:10.1007/s11104-011-0948-y.

533 Qian, Kezhen, Ajay Kumar, Hailin Zhang, Danielle Bellmer, and Raymond Huhnke. 2015.

$534 \quad$ "Recent advances in utilization of biochar." Renewable and Sustainable Energy Reviews 42: 1055-

$535 \quad$ 1064. doi:10.1016/j.rser.2014.10.074.

536 Richardson, I. G. 2008. "The calcium silicate hydrates." Cement and Concrete Research 38: 137-158.

537 doi:10.1016/j.cemconres.2007.11.005.

538 Shi, Zhenguo, Barbara Lothenbach, Mette Rica Geiker, Josef Kaufmann, Andreas Leemann,

539 Sergio Ferreiro, and Jørgen Skibsted. 2016. "Experimental studies and thermodynamic

540 modeling of the carbonation of Portland cement, metakaolin and limestone mortars." Cement

541 and Concrete Research 88: 60-72. doi:10.1016/j.cemconres.2016.06.006.

542 Stutzman, P. 2004. "Scanning electron microscopy imaging of hydraulic cement microstructure."

543 Cement and Concrete Composites 26: 957-966. doi:10.1016/j.cemconcomp.2004.02.043.

544 Tan, Xiaofei, Yunguo Liu, Guangming Zeng, Xin Wang, Xinjiang Hu, Yanling Gu, and

545 Zhongzhu Yang. 2015. "Application of biochar for the removal of pollutants from aqueous

546 solutions." Chemosphere 125: 70-85. doi:10.1016/j.chemosphere.2014.12.058.

547 Taut, T., R. Kleeberg, and J. Bergmann. 1998. "The new Seifert Rietveld program BGMN and its

548 application to quantitative phase analysis." Edited by H. Morawiec and D. Stroz. Proocedings of

Berti, February 8, 
549 the XVII international conference. 87-92.

550 Tremblay, H., J. Duchesne, J. Locat, and S. Leroueil. 2002. "Influence of the nature of organic

551 compounds on fine soil stabilization with cement." Canadian Geotechnical Journal 39: 535-546.

552 doi:10.1139/t02-002.

553 Wang, Lei, Liang Chen, Daniel C. W. Tsang, Binglin Guo, Jian Yang, Zhengtao Shen, Deyi Hou,

$554 \quad$ Yong Sik Ok, and Chi Sun Poon. 2020. "Biochar as green additives in cement-based

555 composites with carbon dioxide curing." Journal of Cleaner Production 258.

556 doi:10.1016/j.jclepro.2020.120678.

557 Woolf, D., J. E. Amonette, A. Street-Perrot, J. Lehman, and S. Joseph. 2010. "Sustainable biochar

558 to mitigate global climate change." Nature Communications 1: 1-9. doi:10.1038/ncomms1053.

559 Zhao, Sheng, Baoshan Huang, and Philip Ye. 2014. "Laboratory evaluation of asphalt cement

560 and mixture modified by bio-char produced through fast pyrolysis." Pavement Materials,

561 Structures, and Performance. American Society of Civil Engineers.

562 doi:10.1061/9780784413418.015.

563

564

565

566

567

568

569

570

Berti, February 8, 
$571 \quad$ List of Tables

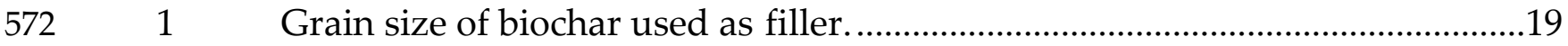

$573 \quad 2$ Results of Rietveld on XRD patterns at 7 days ...............................................20

574 3 Rietveld refinement of sample E XRD patterns 7, 28 and 120 days.............21

575

576

577

578

579

580

581

582

583

584

585

586

Berti, February 8, 
TABLE 1. Grain size of biochar used as filler.

588

592

593

594

595

596

597

598

599

600

601

602

603

604

605

606

607

608

609

610

Berti, February 8, 
612

613

614

\begin{tabular}{l|l|l|l|l|l|l}
\hline Mineral & Control & A & B & C & D & E \\
\hline
\end{tabular}

Hydration products

\begin{tabular}{l|l|l|l|l|l|l}
\hline Portlandite & 19.9 & 8.49 & 9.86 & 16.7 & 22.6 & 13.6 \\
Calcite & 12.25 & 19 & 18.8 & 17.6 & 19.2 & 18.8 \\
C-S-H & 16.6 & 13.5 & 13.4 & 15.9 & 12.3 & 11.4 \\
Monocarboaluminate & 0.0 & 5.3 & 5.3 & 6.4 & 4.4 & 6.2 \\
\hline
\end{tabular}

Cement paste

\begin{tabular}{l|l|l|l|l|l|l}
\hline$C_{2} S$ & 41.1 & 34 & 35.2 & 34.3 & 28.3 & 38.1 \\
$C_{4} A F$ & 3.4 & 1.2 & 8.4 & 5.6 & 9.6 & 3.0 \\
\hline Other components \\
\hline Quartz & 3.8 & 1.2 & 1.4 & 0.9 & 0.8 & 2.0 \\
Cellulose & 0 & 5.0 & 5.9 & 2.5 & 1.6 & 5.8 \\
\hline
\end{tabular}

616 
TABLE 3. Rietveld refinement of sample E XRD patterns 7, 28 and 120 days.

\begin{tabular}{l|l|l|l}
\hline Mineral & 7 Days & $\mathbf{2 8}$ Days & 120 days \\
\hline \multicolumn{4}{l}{ Hydration products } \\
\hline Portlandite & 13.6 & 5.7 & 23.2 \\
Calcite & 18.8 & 39 & 32.2 \\
C-S-H & 11.4 & 5.6 & 9.7 \\
Monocarboaluminate & 6.2 & 8.1 & 6.3 \\
\hline Cement paste & 38.1 & 24.3 & 16.0 \\
\hline$C_{2} S$ & 3.0 & 4.3 & 4.9 \\
$C_{4} A F$ & \multicolumn{5}{l}{} \\
\hline
\end{tabular}




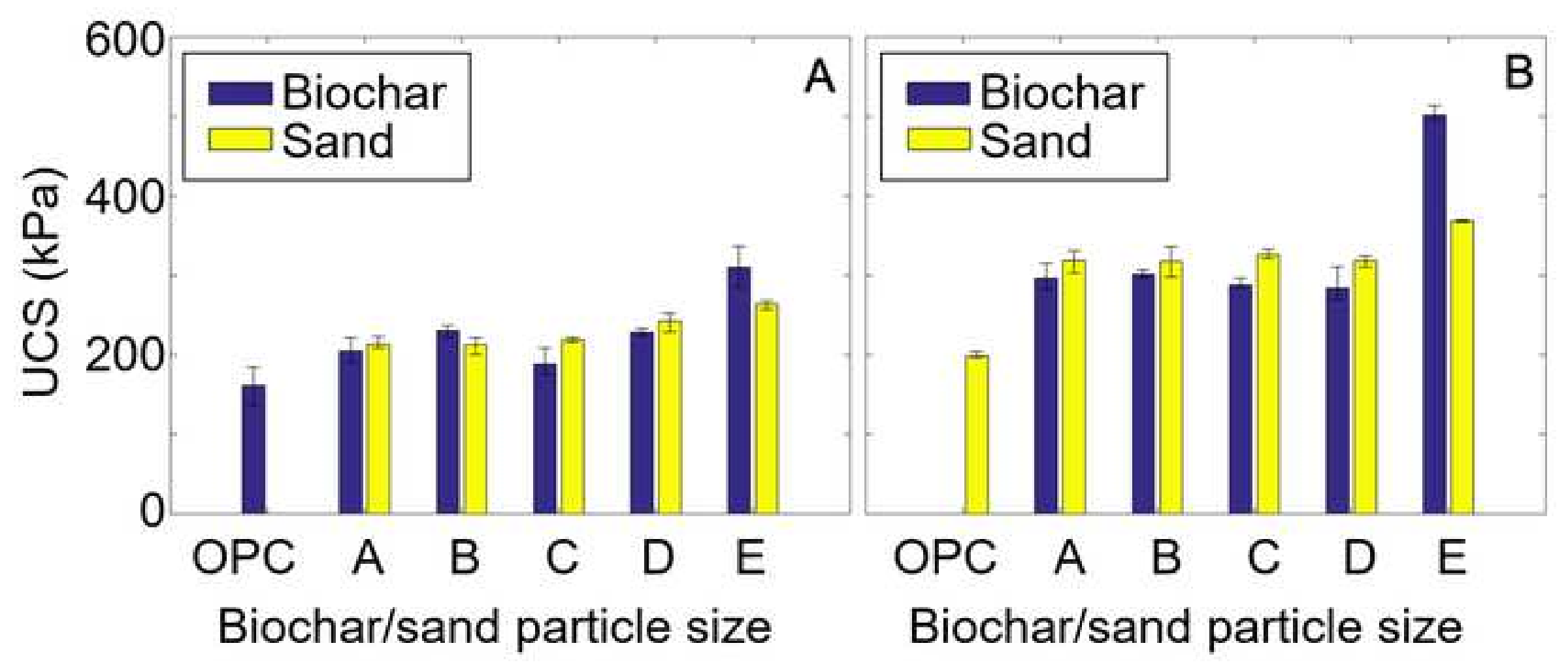



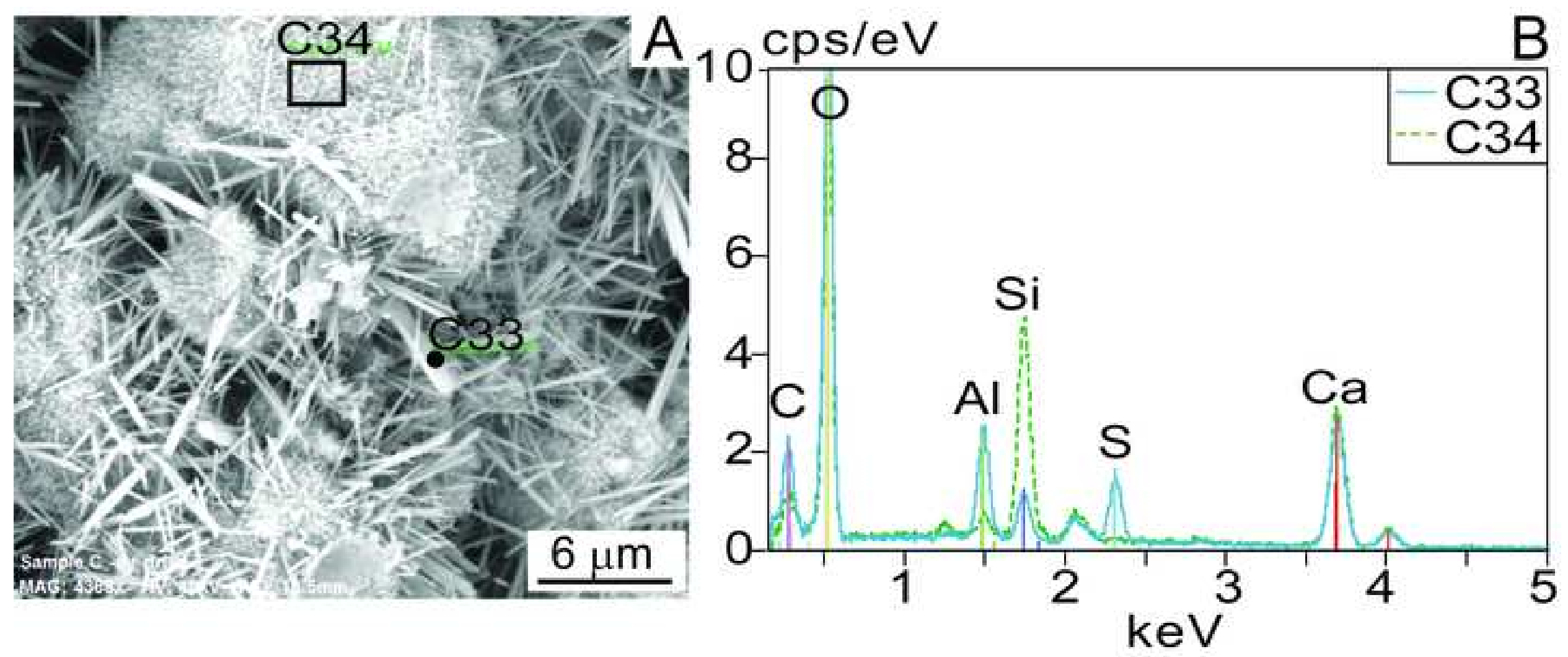

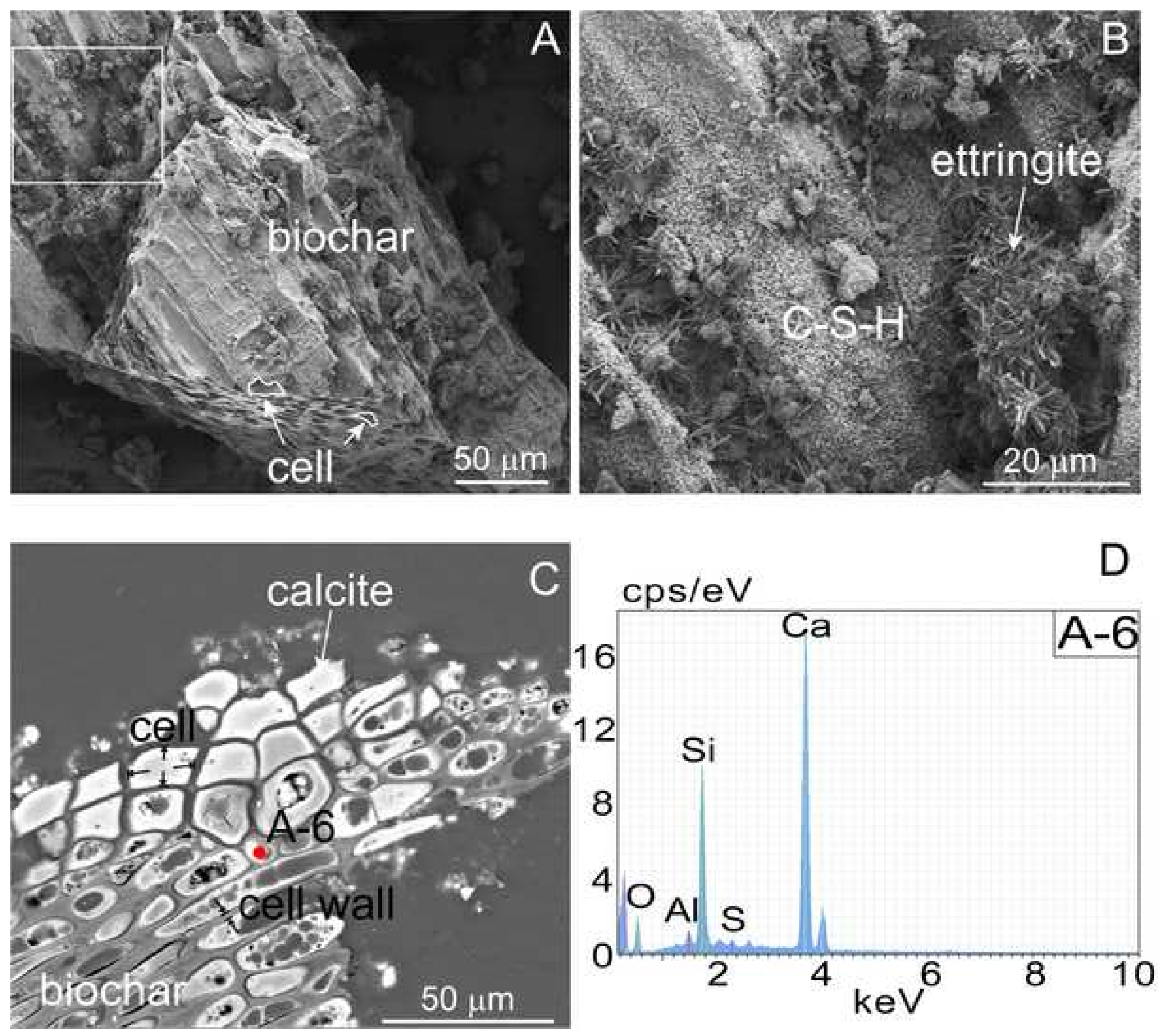


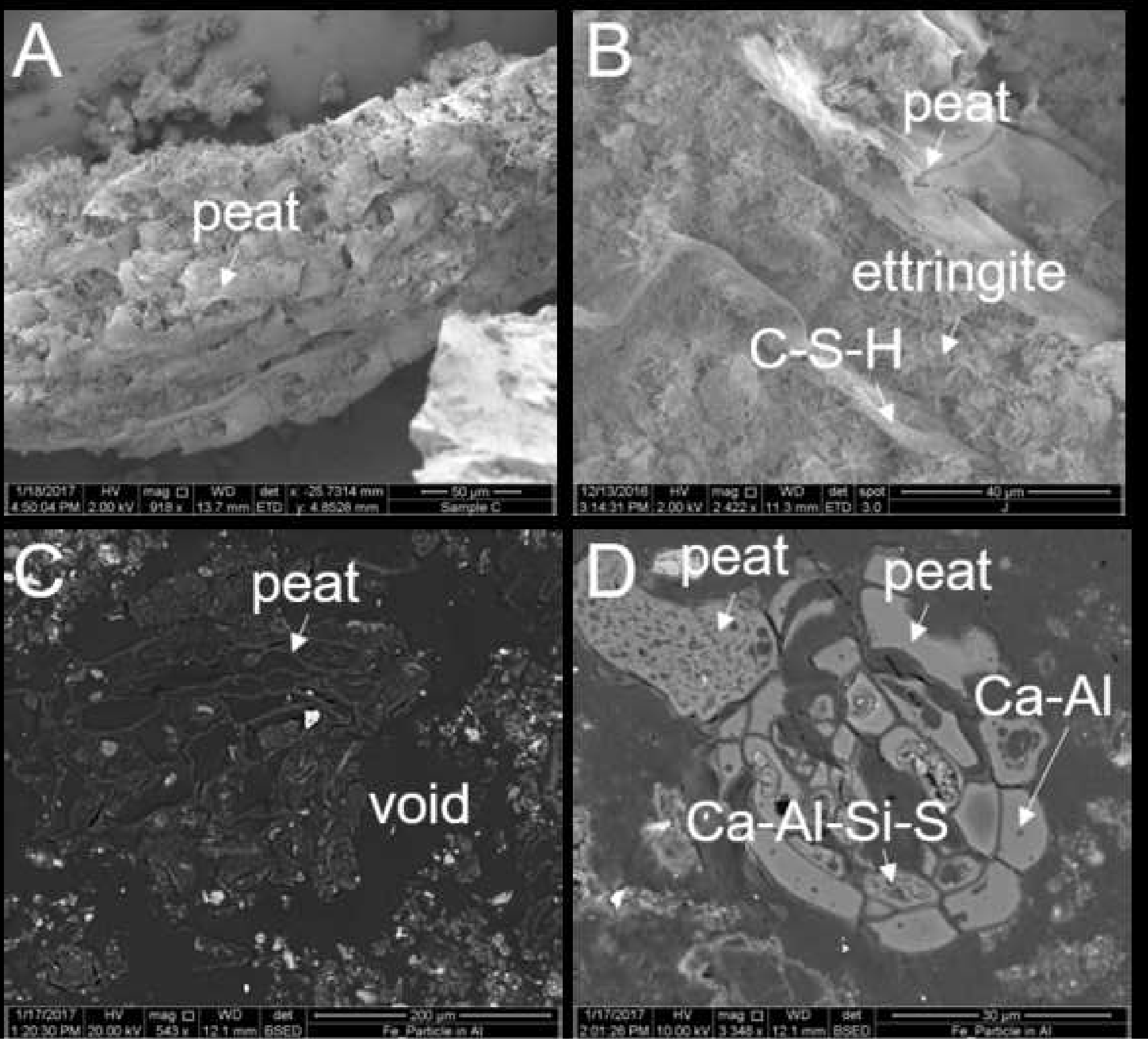



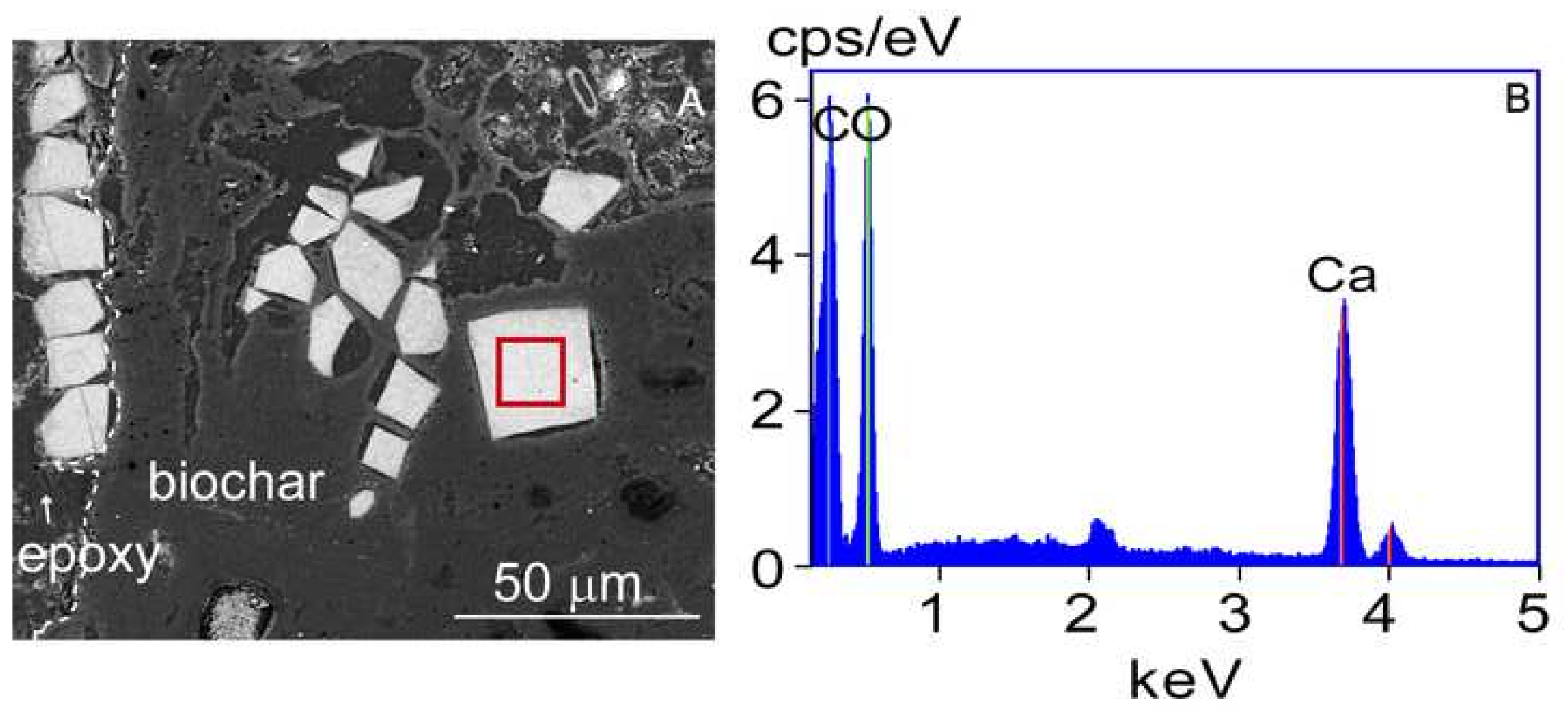


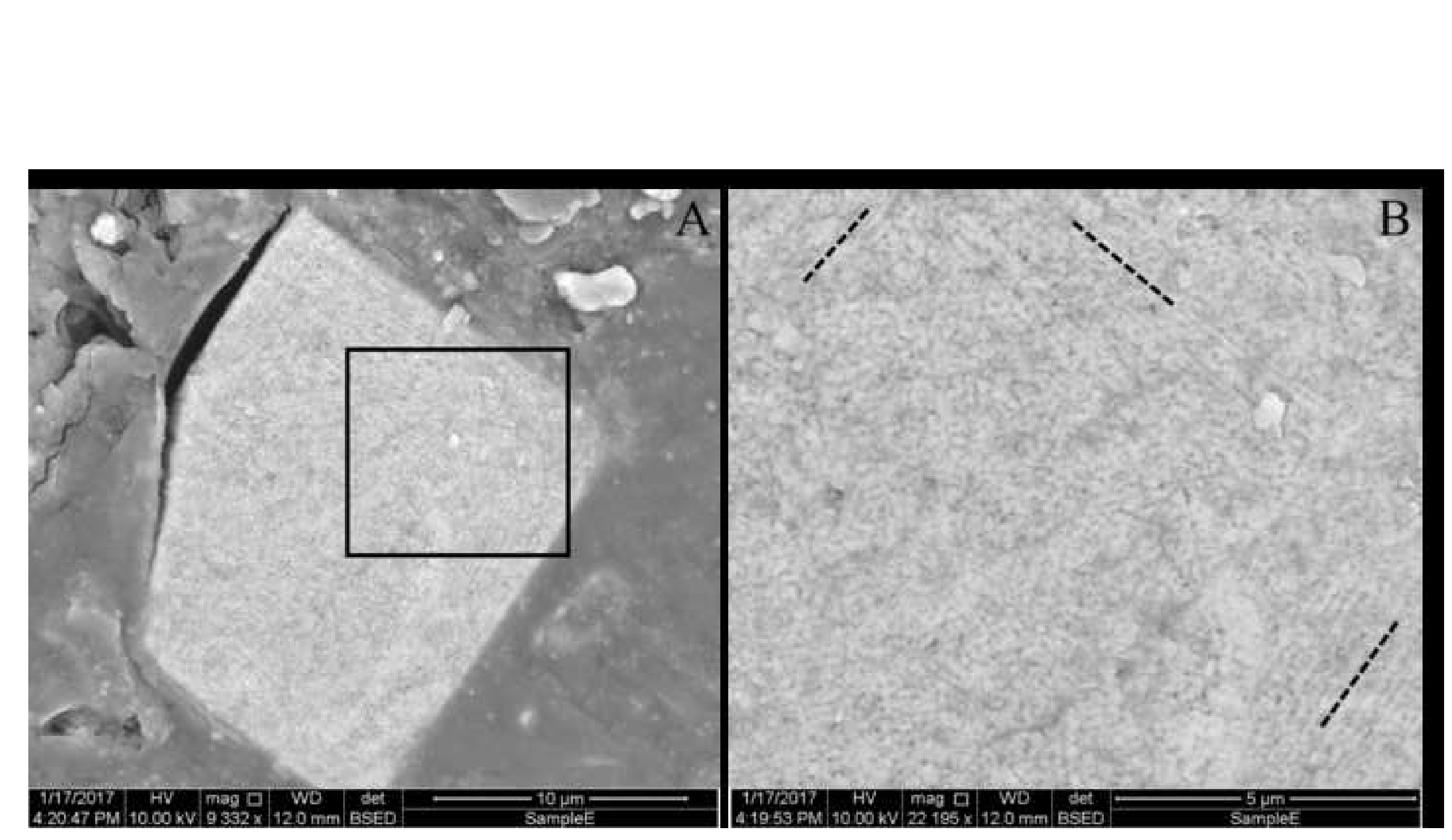




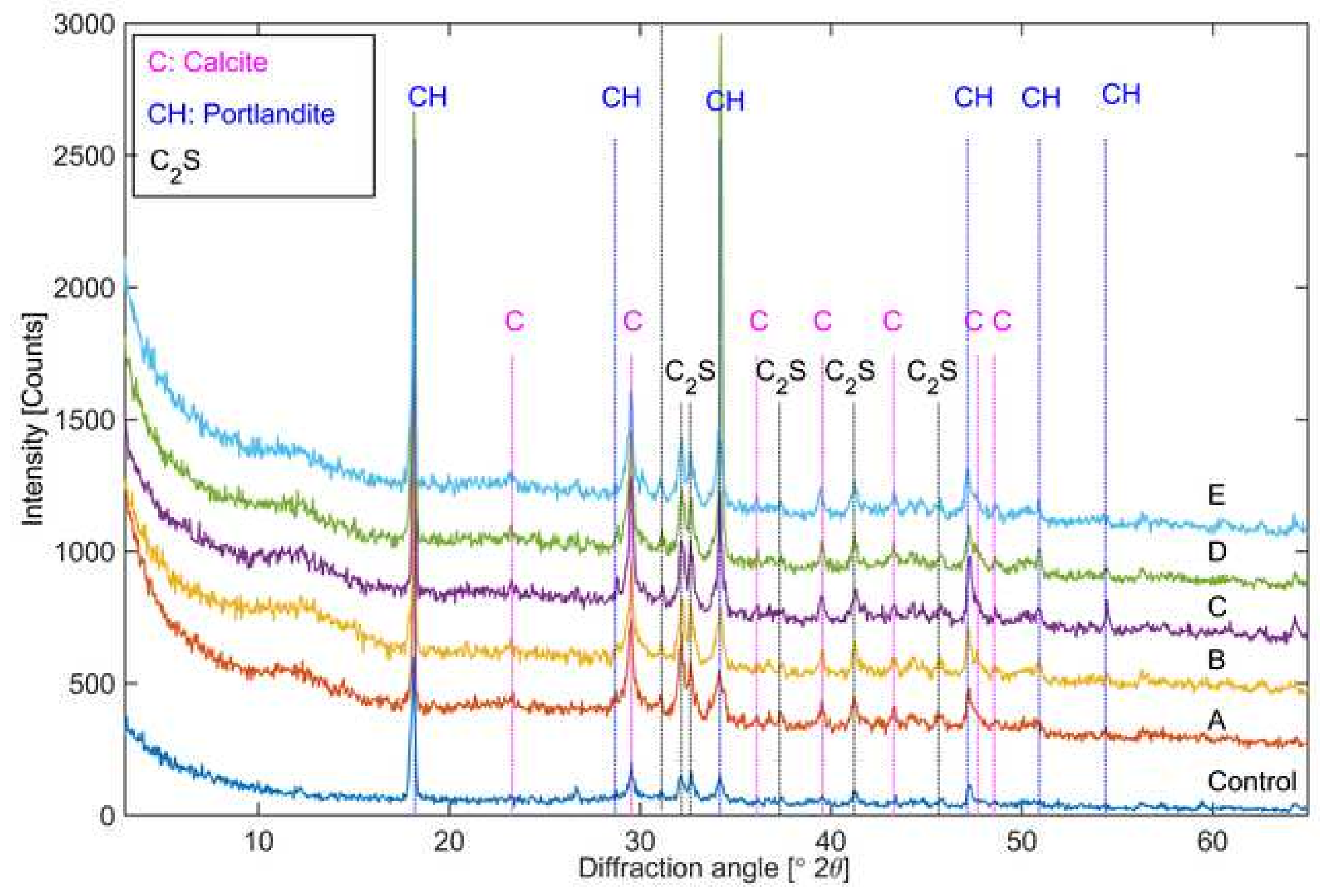




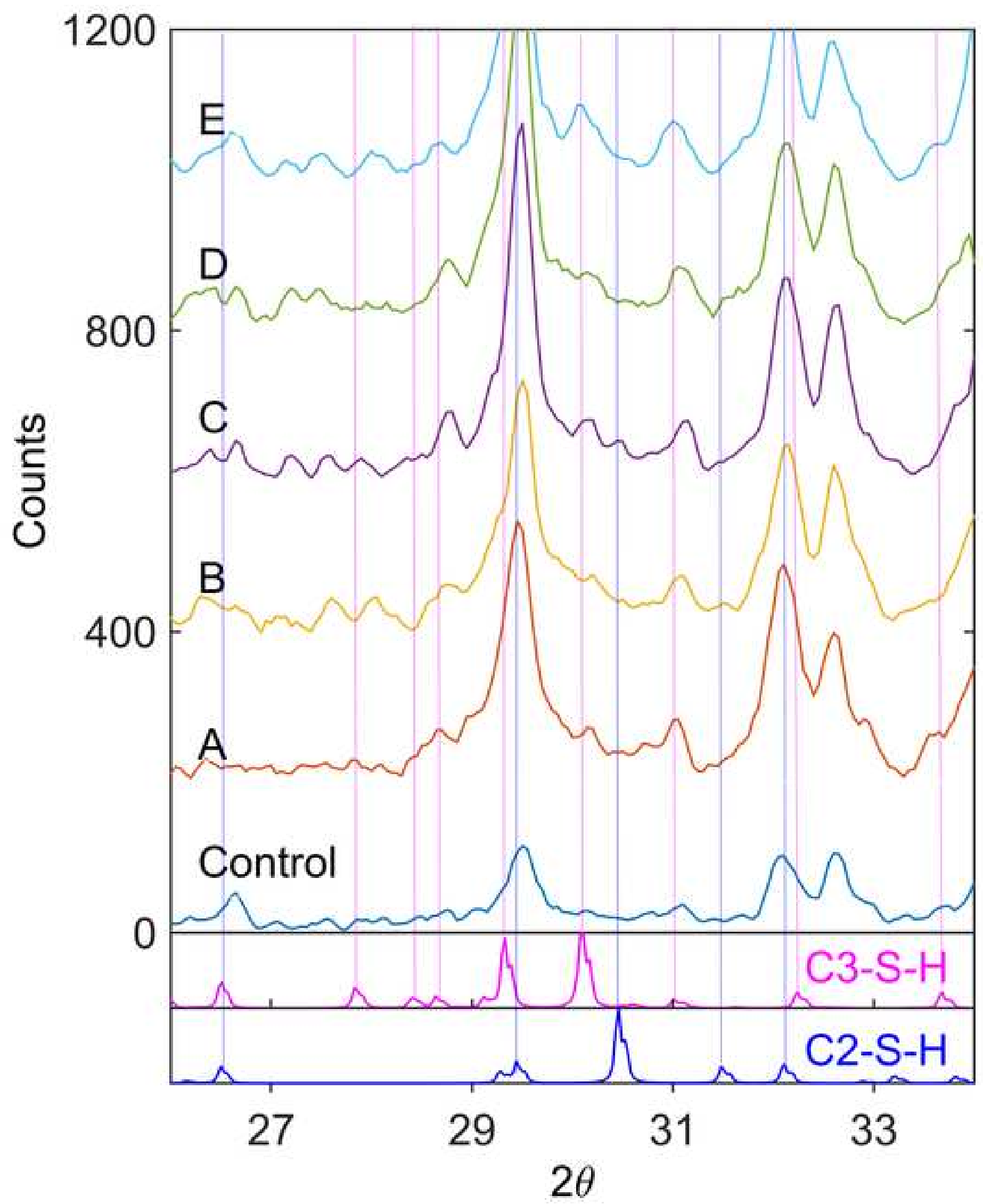




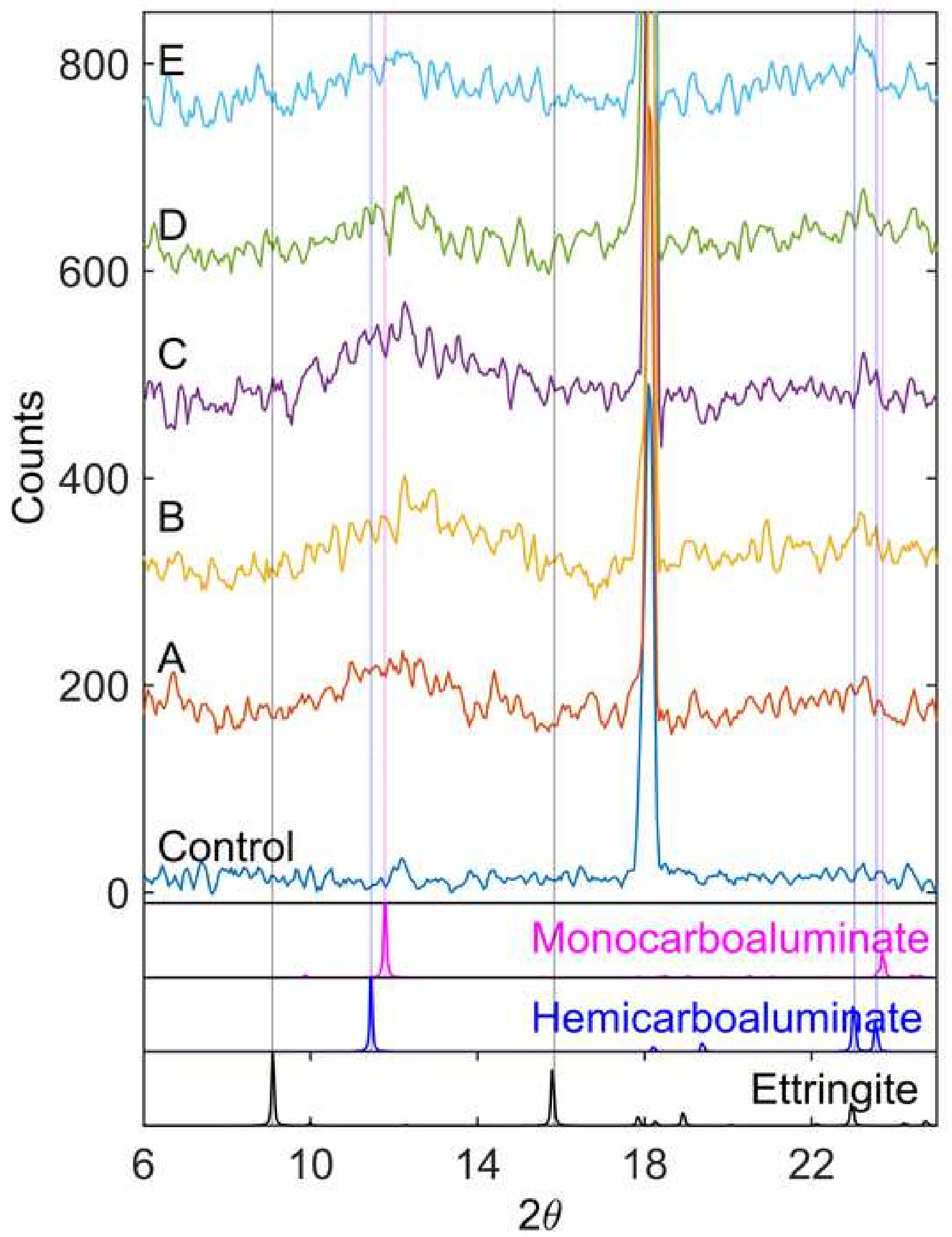




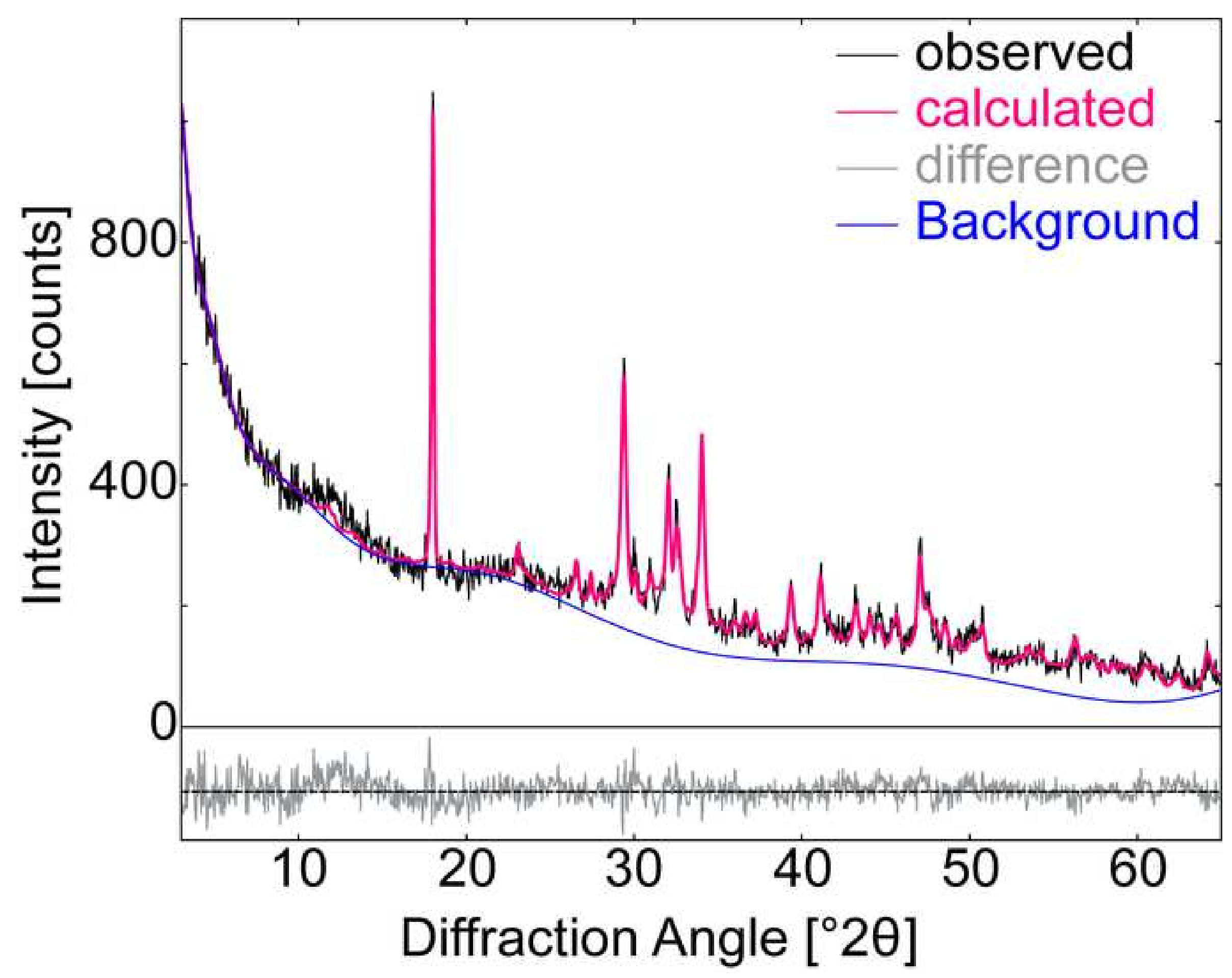




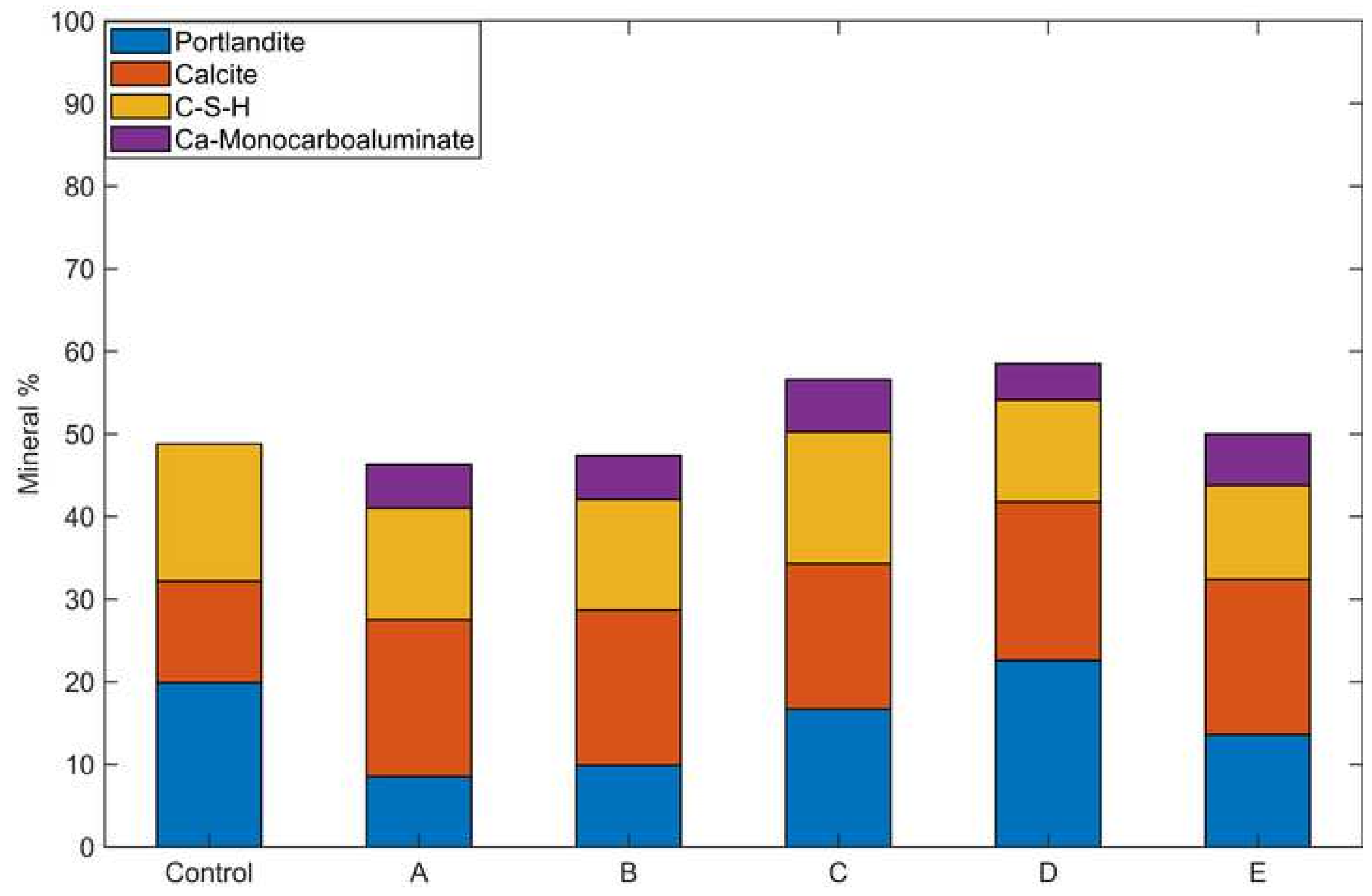




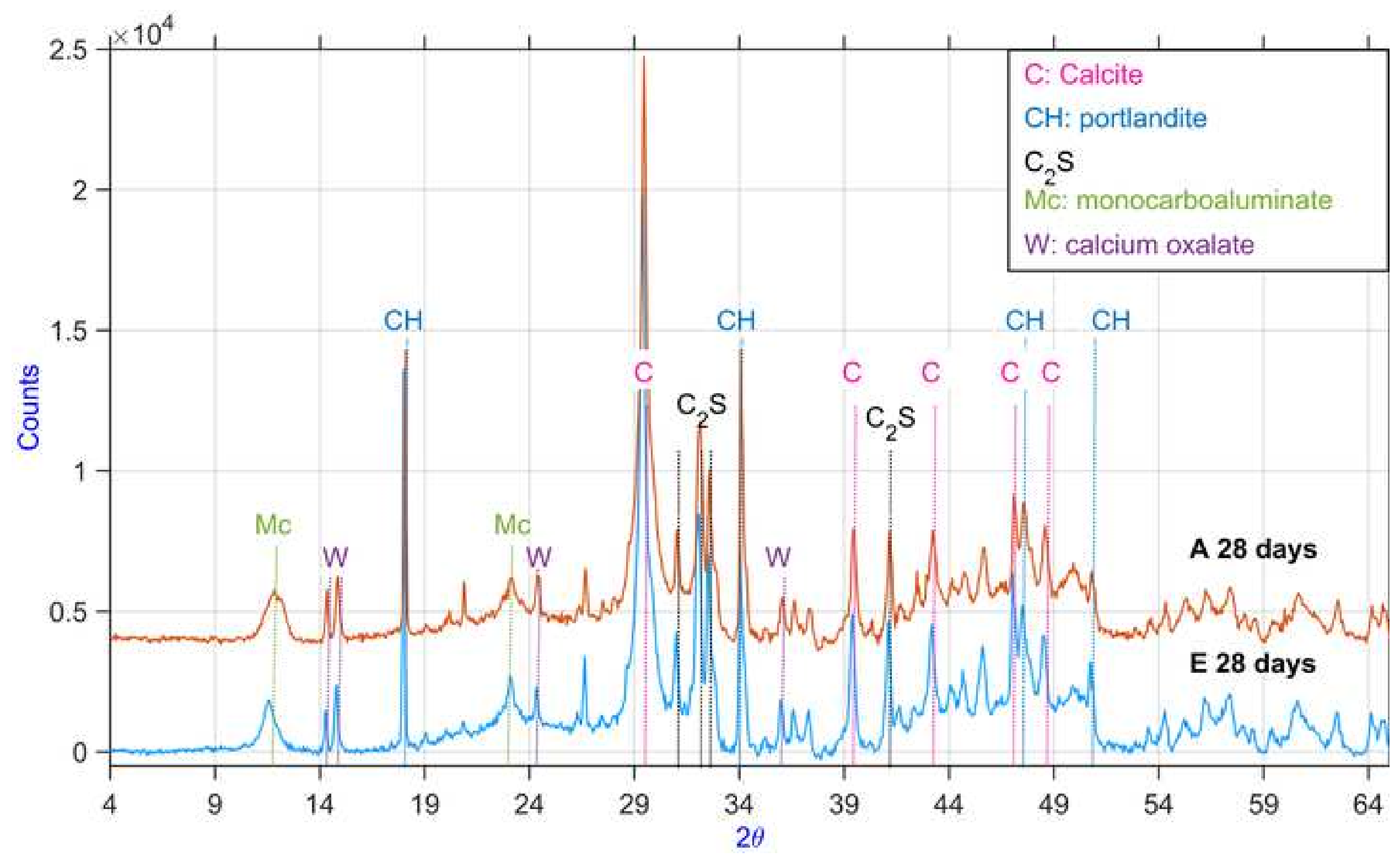




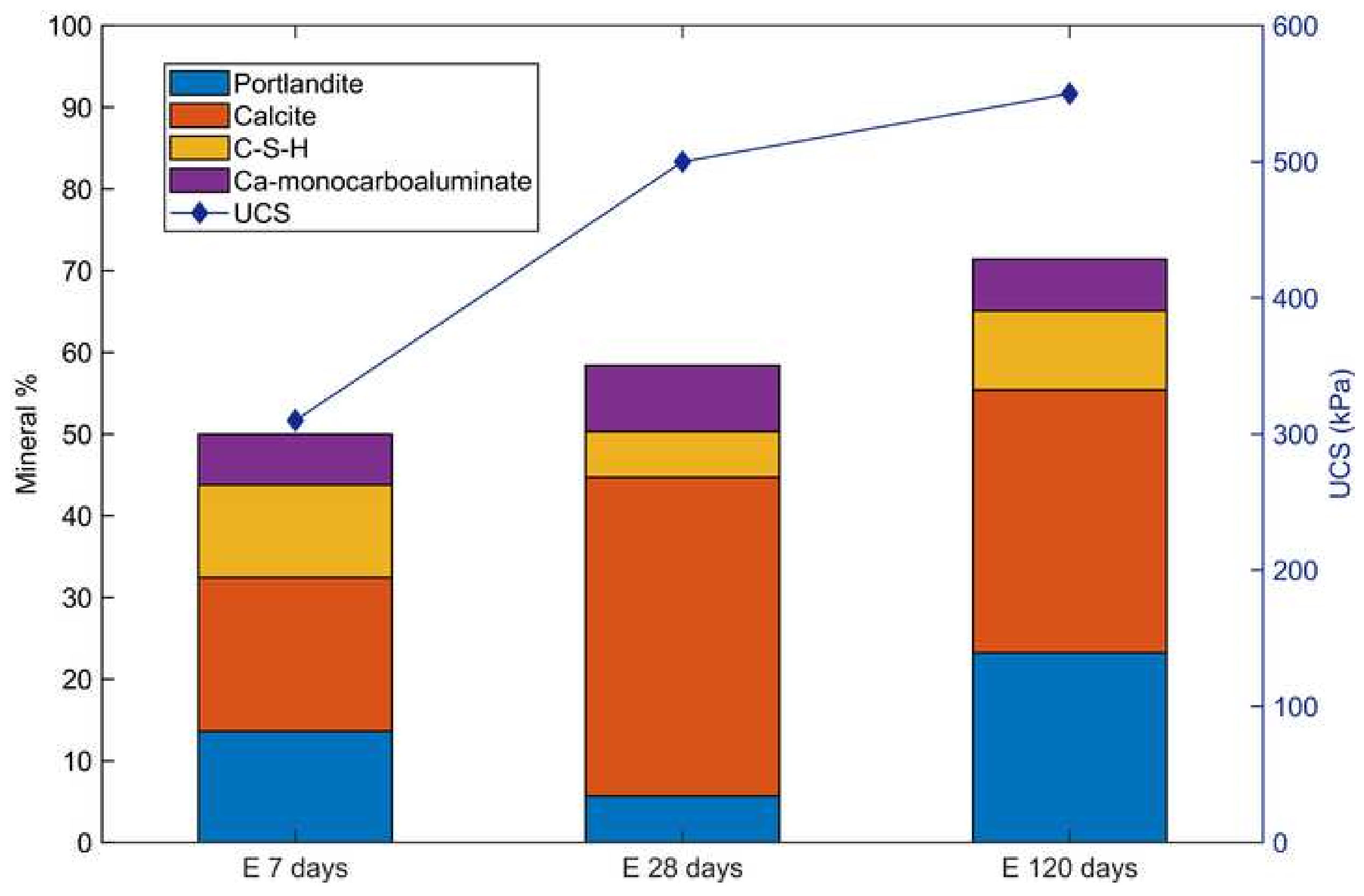



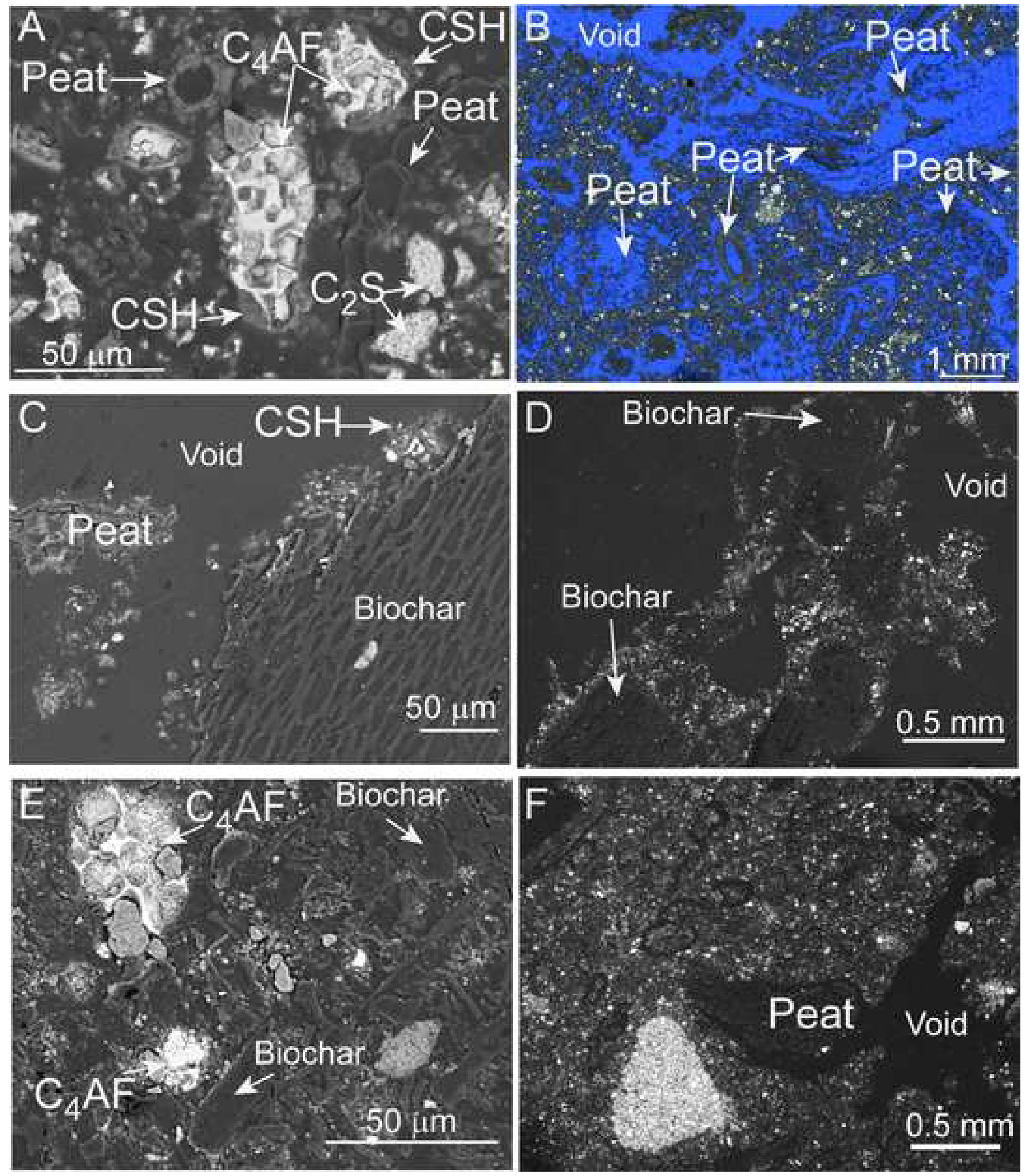
Fig. 1. UCS in OPC-stabilized peat with 5 differently graded biochar filler compared to a sand filler after curing for: A) 7 days; B) 28 days.

Fig. 2. SEM of hydration products in the peat-OPC-biochar mixture. A) SEM image of CS-H coating and ettringite needles. B) EDS spectra collected at point C33 and area C34.

Fig. 3. Cement hydration on biochar surface. A) SEM of air-dried chip taken from sample C. B) Higher magnification of area marked by white rectangle in A. C) SEM-BSE micrograph of a polished cross section of biochar. Examples of cells and cell walls used for measurements are shown. D) EDS spectrum collected from the point marked A-6 shows composition of $\mathrm{Ca}, \mathrm{Si}$ and $\mathrm{O}$.

Fig. 4. SEM of peat fragments. A) peat fragment in air-dried chip of a biochar-filler sample. B) peat fragment in air-dried chip of control sample. C) SEM-BSE of control sample, after embedding and polishing. D) SEM-BSE of peat fragment in embedded and polished control sample.

Fig. 5. Microcrystalline calcium carbonate at the edge of biochar. A) SEM-BSE micrograph. B) EDS spectrum from square ROI.

Fig. 6. A) SEM-BSE micrograph of microcrystalline calcium carbonate. B) growth bands are marked by dotted black lines.

Fig. 7. XRD pattern of peat-biochar-OPC, at 7 days of hydration. The position of the most intense reflections of calcite (pdf 00-005-0586), portlandite (pdf 00*044-1481) and C2S (pdf 00-033-0302) are marked. 
Fig. 8. Region of the XRD pattern between 22 and $32^{\circ} 2 \theta$. The bottom graphs show the model XRD pattern of two C-S-H phases: dellaite (pdf 04-011-1311) and rosenhahnite (pdf 04-012-8453).

Fig. 9. Two-theta interval of XRD pattern where AFm and Aft peaks occur. The bottom graphs show model peaks of monocarboaluminate (COD 2007668), hemicarboaluminate (COD 2105251), and ettringite (pdf 04-011-5267).

Fig. 10. Rietveld refinement results of sample E XRD. The experimental pattern is shown in black, the curve calculated by Rietveld refinement is in magenta, the gray curve in the bottom graph is the difference between experimental and calculated curves.

Fig. 11. Hydration minerals at seven days. The bar plots show the proportions of hydration minerals in the five samples with biochar filler and in the control. Mineral fractions are normalized to the crystalline portion.

Fig. 12. XRD patterns at 28 days of curing, for samples A and E.

Fig. 13. Progression of OPC hydration and UCS over 120 days, for sample E. Stacked bars show the hydrated mineral fractions at 7, 28 and 120 days. The line plot shows the UCS increase.

Fig. 14. SEM-BSE micrographs of embedded and polished samples show the spatial distribution of peat, OPC and biochar. A) control sample, medium magnification B) control sample, low magnification. C) Sample B, medium magnification. D) Sample B, low magnification. E) Sample E, medium magnification. F) Sample B, low magnification. 